\title{
LOS DERECHOS HUMANOS COMO TRIUNFOS POLÍTICOS EN EL ESTADO CONSTITUCIONAL: EL DILEMA ENTRE DEMOCRACIA COMUNITARIA Y LIBERAL EN RONALD DWORKIN*
}

\author{
HUMAN RIGHTS AS POLITICAL TRUMPS IN CONSTITUTIONAL STATES. \\ THE DILEMMA BETWEEN LIBERAL AND COMMUNITARIAN DEMOCRACY \\ IN RONALD DWORKIN
}

\author{
Rafael Enrique AGUILERA PORTALES**
}

\section{Resumen:}

En la visión iusfilosófica de Dworkin constatamos que el razonamiento jurídico depende en gran medida del razonamiento moral, en el sentido en que los principios morales juegan un papel importante y decisivo en el razonamiento jurídico, especialmente en los casos difíciles. Según el profesor Calsamiglia, el filósofo norteamericano intenta construir una tercera vía entre el iusnaturalismo e iuspositivismo. En mi opinión, considero que no se trata de una tercera vía, sino en la recuperación y restauración de un iusnaturalismo moderado, crítico y progresista que trata de defender una serie de valores compartidos. La necesidad de aceptar y respetar esos valores es imperiosa y urgente en nuestra actual sociedad. Sin duda, éste es uno de los aspectos más positivos y relevante de la teoría de Dworkin, el reconocer y otorgar un papel predominante dentro de la teoría político-jurídica a los principios y valores en las decisiones políticas y jurídicas.

* Artículo recibido el 19 de agosto de 2014 y aceptado para su publicación el 5 de noviembre de 2014.

** Profesor titular de Filosofia del derecho y Derecho político de la Facultad de Derecho y Criminología de la Universidad Autónoma de Nuevo León. Doctor por la Universidad de Málaga (España), miembro del Sistema Nacional de Investigadores (Conacyt), nivel 2. 


\section{RAFAEL ENRIQUE AGUILERA PORTALES}

\section{Palabras clave:}

Ronald Dworkin, liberalismo, democracia, valores constituciones, iusnaturalismo, positivismo jurídico.

\section{Keywords:}

Ronald Dworkin, Liberalism, Democracy, Morality and Law, Constitutions, Natural Law Theory, Legal Positivism. 


\section{LOS DERECHOS HUMANOS COMO TRIUNFOS}

SumARIO: I. Introducción. II. La función de la filosofía politica y jurídica. III. Democracia comunitaria y liberalismo politico. IV. La igualdad como valor normativo, axiológico y politico fundamental del Estado constitucional. V. Concepción ontológica juridico-politica en Dworkin. VI. Los derechos humanos como triunfos politicos en el Estado constitucional. VII. Conclusiones. VIII. Bibliografia.

\section{INTRODUCCIÓN}

En la actualidad, Ronald Dworkin constituye una de las figuras más relevantes, prestigiosas y señaladas de la filosofía política y jurídica contemporáneas. Su enorme éxito se debe fundamentalmente a una descripción sugerente, propia y original de los problemas por los que atraviesa la teoría política y jurídica en la actualidad. Dworkin es un escritor prolifico, fecundo e inagotable, un conversador $\mathrm{y}$ discutidor incansable de numerosas cuestiones iusfilosóficas. Como pensador ha mostrado una gran amplitud de intereses: teoría ética, estética, economía, filosofia del lenguaje y lógica, política y jurisprundencia. Su gran mérito ha consistido en provocar la discusión filosófica más allá de los limites estrictamente académicos y llevarla a ámbitos muy variados y plurales, a públicos que en principio no están interesados en los problemas específicos de la filosofia politica y jurídica. Como profesor de Oxford y New York ha sabido no sólo utilizar la academia para abordar numerosos problemas sociales sino salir a la plaza pública como comentador de la política del día desde las páginas del New York Book Review.

"La obra de Dworkin ha originado una polémica sin precedentes en la historia de la filosofia político-jurídica. Probablemente es la primera vez que los trabajos de un filósofo del derecho despiertan interés y la crítica de constituciona- 
listas, sociólogos, filósofos, economistas, politólogos y estudiosos de la ética" 1 .

Uno de los grandes méritos de la filosofía de Dworkin consiste en el enfoque del Derecho desde la perspectiva de la integridad, sin duda una perspectiva que arremete contra la concepción simplista y reduccionista que posee actualmente el positivismo y formalismo jurídico que considera al Derecho fundado en reglas exclusivamente. E1 Derecho, plantea Dworkin, es una actitud muy especial: "es una actitud interpretativa, autoreflexiva, dirigida a la politica en el sentido más amplio". ${ }^{2}$

Sin duda, otro gran componente de su filosofia jurídica es la interesante vinculación que realiza entre derecho y pensamiento filosófico a partir de las fuentes de la filosofía del segundo Wittgenstein, la notable influencia de Rawls, Nozick y Hart con la importancia que otorga a la Hermenéutica y la crítica literaria.

La filosofia, desde sus inicios en Grecia, ha tratado de explicar y justificar las discrepancias entre derecho ideal justo (dikeia) y derecho real (nomos) variable, contaminado y menos perfecto. La justicia era la virtud por excelencia, para la filosofia platónica, aristotélica y estoica, así como para los jurisconsultos romanos. Esta concepción de justicia era entendida dentro de una concepción más amplia y armónica de los distintos órdenes normativos que regulan la conducta humana. La reminiscencia del ethos, así como el ideal de un orden jurídico y una vida política sustentados sobre la moral condujo a una estricta integración de los tres ámbitos normativos de conducta práctica. Así pues, la visión griega defendió una integración absoluta donde: "la moral (ethos) posee un significado omnicomprensivo abar-

1 Casamiglia, Albert, "Dworkin y el enfoque de la integridad", Revista de Ciencias Sociales, Chile, Universidad de Valparaíso, 1945, pp. 45-68, p.45.

2 Casamiglia, Law`s Empire, Harvard University Press, Cambridge, Londres, 1986, p. 413. "It is an interpretive, sef-reflexive attitude addressed to politics in the broaest sense". 
cador de las demás normatividades". ${ }^{3}$ En el mundo griego, la triada moral, política y derecho se encontraban indisolublemente unidos, el sentimiento de pertenencia a la polis y el respecto absoluto a sus leyes marcaban la pauta a seguir. Sócrates fue un testimonio vivo, ejemplar y coherente de este pensamiento ético-jurídico, ${ }^{4}$ su planteamiento filosófico le llevó a elegir y morir por Atenas, pues pensaba que las leyes (nomos) pueden ser criticables, revisables y reformables; pero, ante todo, deben ser veneradas y obedecidas por los ciudadanos como factor de cohesión e integración social en la polis.

\section{LA FUNCIÓN DE LA FILOSOFÍA POLÍTICA Y JURÍDICA}

La filosofia jurídico-política, históricamente, ha tratado de buscar y ofrecer una hegemonía de valores y principios normativos, ${ }^{5}$ proporcionar un ideal orientativo y regulador de conducta práctica para todos los ciudadanos dentro de una concepción pluralista e igualitaria de democracia. Su función sigue siendo moderar las diferentes interpretaciones teóricas del ideal politico de libertad e igualdad para ayudarnos a defender un mejor modelo democrático de convivencia humana, y de este modo, profundizar en sus instituciones políticas y jurídicas para extender estos valores a todas las prácticas políticas y sociales posibles.

3 Perez Luño, A. E., Teoría del derecho. Una concepción de la experiencia jurídica, 1997, p. 136.

4 Rodríguez Andrados, F., Mustración y politica en la Grecia clásica, Biblioteca de Política y sociología, Rev. de Occidente, Madrid, 1966. Llambias de Azavedo, J., El pensamiento del Derecho y del Estado en la antigüedad, Buenos Aires, Librería jurídica, 1956. Ruiz Miguel, Alfonso, Una filosofía del derecho en modelos históricos: de la antigüedad a los inicios del constitucionalismo, Madrid, Trotta, 2000. Rubio Carracedo, J., "Paradigmas de la obligación política”, Sistema, núm. 85, 1990, pp. 89-106. Recogido posteriormente en su libro Paradigmas de la politica. Del Estado justo al estado legitimo (Platón, Marx, Rawls, Nozick), 1990.

5 Ruiz Miguel, Alfonso, Una filosofía del derecho..., cit. 
En el momento presente, asistimos a una época de profunda renovación de los estudios filosófico-jurídicos, un creciente interés por parte de los propios juristas hacia la Filosofia política y jurídica, incluso podemos afirmar que nos encontramos en una etapa de mayor compenetración entre Filosofía política y jurídica, aunque, también es cierto que una gran mayoría de los juristas permanece ligado a los aspectos exclusivamente técnicos y formales del derecho, en sus aplicaciones prácticas inmediatas, reve- lando cierto margen de desconfianza y reserva hacia las especulaciones filosófico-jurídicas. Normalmente, se ha reconocido una cierta importancia a la Filosofía política y jurídica en el plano formativo dentro de un marco de cultura jurídica general, pero no hemos profundizado sobre las aportaciones metodológicas, hermenéuticas y axiológicas de la Filosofía jurídica.

No obstante, todavía persiste una situación intelectual profundamente deteriorada por un enconado y arraigado positivismo y formalismo jurídico, ${ }^{6}$ sobre todo en la práctica jurídica, que se encuentra afortunadamente en retirada, producto de una radical proceso de positivación general del conocimiento que ha provocado, en primer lugar, un abandono y descrédito de la filosofia como saber metafísico inútil, baladí y estéril, en segundo lugar, una confusión y desorientación de nuestra disciplina que no encuentra su posición o lugar específico en el conjunto general del saber. En tercer lugar, un pérdida del sentido total del mundo unida a una fuerte ausencia de vida espiritual e intelectual, en cuarto lugar, una reducción simplista del conocimiento a mera técnica instrumental (tecnociencia). Este imperio de la racionalidad instrumental (discurso tecnocrático) afecta al mundo político entendido como tecnocracia y al mundo jurídico concebido como ingeniería social.

Ronald Dworkin es consciente de cómo la filosofia jurídica y politica ha sufrido, en los últimos tiempos, un fuerte

6 Welzel, H., Introducción a la filosofía del derecho. Derecho natural y justicia material, trad. de F. Gonzalez Vicén, Madrid, Aguilar, 1971. 
aislamiento, segregación y marginación respecto a otras disciplinas normativas. No obstante, a lo largo de su carrera ha ido reivindicando y defendiendo progresivamente la importancia de considerar la filosofia jurídica como parte relevante de la filosofia moral y politica, ${ }^{7}$ y a su vez, de la filosofia en general. Por tanto, "cualquier teoria del derecho competente debe ser ella misma un ejercicio de teoria moral y politica normativa". 8

La filosofia jurídica sigue cumpliendo una función normativa de enorme relevancia y significación metodológica, ontológica, hermenéutica y axiológica. Nos encontramos, así pues, ante una disciplina normativa que pretende justificar reflexiva y críticamente todo sistema político y jurídico. El mismo Cicerón planteaba en su famoso tratado De legibus que el verdadero conocimiento del derecho debe extraerse del "corazón mismo de la filosofía". "Así sacamos la conclusión de que la naturaleza formó al ser humano para que participe y posea el Derecho... Quienes recibieron la razón de la naturaleza recibieron la recta razón, es decir, la ley, que no es otra cosa sino la recta razón que prohíbe y ordena. Y si recibieron la ley, recibieron además al Derecho". ${ }^{9}$ Por consiguiente, nuestra disciplina acomete una empresa intelectual ardua, dificil y controvertible al plantearse problemas como: ¿qué es el derecho?, ¿qué es el poder? ¿qué

7 Cohen, M., Ronald Dworkin and Contemporary Jurisprudente, Londres, Duckworth, 1984; Carrió, G., Principios jurídicos y positivismo jurídico, Buenos Aires, Abeledo Perrot, 1970.

8 Dworkin, La filosofía del derecho, México, Fondo de Cultura Económica, 1980.

9 Cicerón, Sobre las leyes, lib.I, V, 17, Buenos Aires, Ed. Aguilar, p. 42. Desde la época romana, donde surge el Derecho como disciplina autónoma, se ha reconocido a la Filosofia como un saber indispensable para el jurista. Es cierto que durante una gran parte de la historia del pensamiento jurídico, la filosofia ha sido mal utilizada para estructurar sistemas, ideas y preceptos jurídicos con una cierta validez universal para todas las épocas; pero la Filosofia del Derecho, sin duda, tiene una tarea de primera importancia en la organización y fundamentación crítica del corpus de conocimientos jurídicos. 
es la justicia?, ¿qué es la autoridad?, ¿cuándo un derecho es justo?, ¿qué es la legitimidad del derecho?, ¿es incuestionable la obediencia al derecho? Éstos son las interrogantes que se ha planteado históricamente la Filosofia del derecho. Todo sistema político y jurídico precisa de una justificación, un fundamento, una legitimación teórica última. El célebre filósofo y matemático inglés Beltrand Russell opinaba que el valor de la filosofia debemos buscarlo en los problemas que nos plantean, donde las preguntas son más importantes que las respuestas.

[...] Estos problemas amplian nuestra concepción de lo posible, enriquecen nuestra imaginación intelectual y disminuyen la seguridad dogmática que cierra el espíritu de investigación; pero, ante todo, porque por la grandeza del Universo que la filosofia contempla, el espíritu se hace a su vez grande, y llega a ser capaz de la unión con el Universo que constituye su supremo bien". ${ }^{10}$

\section{DEMOCRACIA COMUNITARIA Y LIBERALISMO POLÍTICO}

En términos generales, el liberalismo político dentro del pensamiento político ha defendido el valor de libertad por encima de cualquier privilegio de clase social, es decir, postula la limitación del poder estatal en defensa de la libertad individual. El liberalismo político en la tradición anglosajona es sinónimo de social-democracia o progresismo, en este sentido Dworkin concibe el liberalismo político como aquella corriente de la teoría política moderna cuyo núcleo se fundamenta en la concepción de la igualdad, que denomina concepción liberal de igualdad. En este sentido, Dworkin no es un liberal ni individualista a secas, sino que trata de conciliar la tradición liberal política con el ideal democrático de igualdad politica y social.

10 Russell, Beltrand, Los problemas centrales de filosofía, Barcelona, Paidós, 1992, p.135. 


\section{LOS DERECHOS HUMANOS COMO TRIUNFOS}

En la década de los sesenta y setenta diversos acontecimientos politicos pusieron en cuestión a nivel internacional el liberalismo como teoría política. La línea divisoria entre liberales progresistas y conservadores se hizo muy estrecha, tenue y delicada. No obstante, Dworkin trató de rescatar una concepción de liberalismo político claramente comprometido con políticas públicas de igualdad económica y social.

El ideal del liberalismo como una moral politica fundamental no sólo no es un mito, sino que es una idea necesaria para cualquier relato adecuado de la historia política moderna y para cualquier análisis adecuado del debate político contemporáneo. ${ }^{11}$

En este sentido, los liberales están a favor de la igualdad económica, del internacionalismo, de la libertad de expresión y en contra de la censura, a favor de una creciente igualdad entre razas, géneros y en contra de la segregación ${ }^{12}$, a favor de una tajante separación entre la Iglesia y el Estado, de una mayor protección procesal contra los acusados, de la despenalización de las ofensas morales, con el sexo consentido libremente entre adultos.

Mi proyecto asume, en efecto, una cierta interpretación del papel que la teoría política desempeña en la vida política. Supone que el liberalismo está basado en alguna moral polí-

11 Dworkin, Ronald, Liberalismo, Constitución y Democracia, Buenos Aires, Ed. La isla de la Luna, 2003, p. 13.

12 En pleno siglo XX, décadas de los cincuenta y sesenta, en Estados Unidos de América estaban vigentes en los estados sureños de este país legislaciones segregacionistas anticonstitucionales que establecian la separación de la población negra en escuelas, parques, transportes públicos o restaurantes. El abolicionismo de la esclavitud en Estados Unidos de América no era necesariamente integracionista, con frecuencia se declaraba la doctrina "iguales pero separados". Véase EstèveZ Araujo, J. A., La Constitución como proceso y la desobediencia civil, Madrid, Trotta, 1994; Dworkin, R., Freedom's Law. The Moral Reading of the American Constitution, Cambridge, Mass, Harvard University Press. 
RAFAEL ENRIQUE AGUILERA PORTALES

tica constitutiva que se ha mantenido, en mayor o menor medida, idéntica durante algunos años, y que sigue siendo influyente en la vida política. ${ }^{13}$

La política de la democracia reconoce varios ideales políticos constitutivos independientes entre los que podemos destacar la libertad e igualdad. Dworkin distingue dos modelos o visiones de democracia según la lectura que realicemos: la estadística y la comunitaria. La primera versión estadística se fundamenta en la concepción de que las decisiones políticas se toman en función de los votos o decisiones de los ciudadanos individualmente considerados. La segunda lectura comunitaria de democracia concibe no al individuo sino al pueblo como entidad quien toma las decisiones políticas. Esta última concepción nos remonta a la concepción de voluntad general de Rousseau.

Dworkin defiende el modelo comunitario de democracia por dos razones, en primer lugar porque la descripción comunitaria es más atractiva que la estadística en cuestión de moralidad política. Segundo, la descripción comunitaria ofrece una mejor interpretación de las comunidades politicas canadiense y estadounidense, en la que se incluyen tanto la democracia como las limitaciones constitucionales a la voluntad mayoritaria.

En una democracia genuina, el pueblo gobierna no en forma estadística sino comunitaria. Considera a su nación como una unidad colectiva de responsabilidad, lo cual significa que, en tanto ciudadanos, comparten las responsabilidades que derivan de todo aquello que su gobierno hace en su actuar oficial. ${ }^{14}$

Dworkin quiere resaltar las insuficiencias y deficiencias de la democracia estadística o formal frente a la democracia comunitaria. En una democracia estadística el pueblo constituye una unidad de responsabilidad distintiva, pero no

13 Dworkin, Ronald, Liberalismo, Constitución y Democracia, cit., p. 13.

14 Ibidem, p. 45. 
conforma una unidad colectiva de juicio. Es decir, la democracia se reduce exclusivamente a la elección de unas estructuras de poderes y funciones entre los ciudadanos, los funcionarios y las instituciones. En una democracia estadística se puede dar la paradoja antidemocrática de que una tiranía mayoritaria niegue la justa participación de una minoría de la sociedad. ${ }^{15}$ Este modelo de democracia, por tanto, incurre en una falta de consideración y trato igual hacia todos sus miembros. El liberalismo político de John Stuart Mill nos advierte que el verdadero peligro de la democracia no es el despotismo; sino la tiranía de la mayoría, la tiranía de una colectividad mediocre. La muchedumbre con su imposición de las costumbres puede empobrecer e impedir el desarrollo de los individuos y de un pueblo. Este nuevo y formidable poder de la sociedad puede absorber al individuo y acabar con toda su potencialidad. "No basta, pues, una simple protección contra la tiranía del magistrado. Se requiere, además, protección contra la tiranía de las opiniones y pasiones dominantes; contra la tendencia de la sociedad a imponer como reglas de conducta sus ideas y costumbres a los que difieren de ellos, impidiendo, en lo posible, la formación de individuos diferentes". ${ }^{16}$ En esta misma línea, Dworkin defiende un modelo democrático basado prioritariamente en la igualdad politica.

La democracia está justificada porque garantiza el derecho de cada persona de ser respetada y cuidada; pero en la práctica las decisiones de una mayoría democrática pueden violar ese derecho, de acuerdo con lo que la teoría liberal sostiene que ese derecho requiere. ${ }^{17}$

15 Dworkin sigue la tradición del liberalismo de John Stuart Mill en la defensa o protección del individuo y su libertad frente a la intromisión ilegítima del Estado; pero éste ante todo nos advierte que existe otra intromisión mayor y más peligrosa: la tiranía de la opinión o de la mayoría.

16 Cfr. Stuart Mill, J., Sobre la libertad, Barcelona, Orbis, 1985, p. 85.

17 Dworkin, Ronald, op. cit., p. 30. 
Esta concepción de democracia comunitaria por un lado disuelve la linea divisoria entre justicia sustantiva y procedimental y, por otro lado, precisa tanto de instituciones formales como instituciones formativas que hagan surgir y alimentar dos actitudes democráticas necesarias: la responsabilidad colectiva y juicio individual. En una democracia comunitariamente entendida, las decisiones colectivas deben reflejar igual consideración por los intereses de todos sus miembros. En dicha democracia todos sus miembros generan una unidad colectiva de responsabilidad basada en la reciprocidad, cada miembro desde sus intereses particulares debe ser tomado en cuenta y respetado por la comunidad. La cuestión acerca de cómo la comunidad trata a sus miembros es parte de lo que determina si estos pertenecen, y por lo tanto, si las decisiones políticas son tomadas por una agente colectivo que los incluya. En esta línea, "una sociedad en la que la mayoría distribuye inequitativamente los recursos no es democrática ni justa". ${ }^{18}$

Dworkin propone operar sobre un modelo ideal de sociedad democrática. Una sociedad democrática es una sociedad en la cual se respetan los siguientes principios. Los principios de equidad, justicia, principio de legalidad, integridad. En primer lugar, una sociedad no es democrática si no otorga a todos los miembros de su comunidad igual poder de decisión sobre los asuntos colectivos. El principio de igualdad política viene expresado en la fórmula de dar un voto a cada uno de los individuos. En segundo lugar, el principio de justicia. Este principio se refiere fundamentalmente a los resultados que producen las decisiones, en este sentido, la equidad se refiere al procedimiento y la imparcialidad, mientras la justicia se refiere a los resultados. En tercer lugar, el principio de legalidad, en una sociedad democrática sólo es admisible el poder legitimo jurídicamente, es decir, según los cauces que determine la ley. Una sociedad democrática no puede admitir policias paramilitares ni el uso de la fuerza no jurídica. En cuarto lugar, el principio

18 Ibidem, p. 66. 
de integridad. Una sociedad democrática está bien diseñada si responde a la virtud de la integridad. La virtud de la integridad supone la existencia de unos principios y una organización coherente. Sin duda, este es un aspecto fundamental de la comprensión del Derecho como integridad que desemboca en una hermenéutica o teoría interpretativa: los derechos humanos morales y jurídicos encarnan el modelo de justicia que debe ser actuado por el juez en las resoluciones de los casos.

\section{LA IGUALDAD COMO VALOR NORMATIVO, AXIOLÓGICO Y POLÍTICO FUNDAMENTAL DEL ESTADO CONSTITUCIONAL}

La igualdad es un valor normativo y axiológico referencial1199 que inspira el desarrollo, evolución e implementación de nuestros Estados democráticos y sociales de derecho hacia una mayor integración social, política, jurídica y económica. En nuestra tradición de pensamiento filosófico ha existido una clara contraposición entre libertad e igualdad, 2200 cuyas interpretaciones múltiples y heterogéneas no aclara mucho el intento de fundamentación filosófica, política y constitucional de los derechos fundamentales como expresión nítida y clara de estos valores axiológicos fundamentales. No obstante, actualmente existen propuestas filo-

19 Pérez Luño, Antonio Enrique, Dimensiones de la igualdad, Madrid, Dykinson, 2006, p. 16. Véase Laporta, F., "El principio de igualdad: introducción a su análisis", Sistema, núm. 67, 1985, pp. 3-31. Para ampliar más sobre el tema puede consultarse otro trabajo Aguilera Portales, Rafael "La igualdad como valor normativo, axiológico y político fundamental", en Figueruelo, Ángela, ¿Igualdad ¿para qué?, Granada, Comares, 2007, pp. 15-49.

20 Las tensiones dialécticas entre libertad e igualdad, libertad y seguridad, responsabilidad individual y protección del Estado son inevitables cuando hablamos del desarrollo del Estado Constitucional. Su ambivalencia es una constante pues, por una parte ahonda y profundiza la libertad real del individuo al tratar de reducir su pobreza, miseria e inseguridad, pero por otra, lo expone a un régimen administrativo de exceso de burocracias y disciplina. Rodríguez-Piñero, M. y Fernández, Ma. F., Igualdad y discriminación, Madrid, Tecnos, 1986. 
sóficas sintetizadoras actuales capaces de superar esta tradicional contraposición y antagonismo doctrinal. La filosofia politico-jurídica de Rawls ha tratado de compaginar estos dos grandes valores fundamentales de la libertad e igualdad $^{21}$ a través de una posición claramente conciliadora. Ni individualismo exacerbado, ni igualitarismo que dé lugar a una progresiva uniformidad, homogeneización y anulación de diferencias. Ni individualismo que venda la igualdad a cambio de libertad total, ni igualitarismo que venda, descarte o margine la libertad completamente a favor de la igualdad. Como intelectual liberal, la libertad es la categoría fundamental y principal de su pensamiento, pero sin descartar los otros dos ideales ilustrados, igualdad y fraternidad (solidaridad) que vienen expresados en los dos principios de justicia, el principio de libertad y principio de diferencia, ambos presentes en toda su obra.

John Ralws defiende un "liberalismo politico del Estado de bienestar social", ${ }^{22}$ la idea de que los gobiernos han de prestar a sus ciudadanos el mayor abanico posible de derechos civiles y oportunidades económicas. Cualquier gobierno que no sepa conducirse por normas democráticas, que fracase en la apertura de oportunidades económicas y promoción del bienestar de los ciudadanos menos prósperos y más desamparados estaría violando sus derechos funda- mentales $\mathrm{y}$, por tanto, sus derechos ciudadanos.

Igualmente, Dworkin considera que la igualdad es una virtud fundamental de la democracia. Un gobierno legítimo

21 El filósofo norteamericano John Rawls ha sido uno de los grandes pensadores en conceptualizar la relación entre libertad e igualdad. Rawls es consciente de que no hay libertad sin igualdad. El concepto de igualdad de Rawls no tiene nada que ver con el igualitarismo gregario propio del socialismo real practicado en los regimenes comunistas. Rawls acepta las virtudes del capitalismo y la economía de mercado; pero tratando de paliar las desigualdades que esa economía libre provoca. Rubio Carracedo, J., "Paradigmas de la obligación política", Sistema, cit., pp. 89-106.

22 Ralws, J., El liberalismo politico, trad. cast. A. Doménech, Crítica, 1996, pp. 165 y ss. RALWS John, "Justice as Fairness: Political, not Metaphysical”, Philosophy and Public Affairs, 1990, 14, 1, pp. 223-251. 


\section{LOS DERECHOS HUMANOS COMO TRIUNFOS}

tiene que tratar a todos sus ciudadanos como iguales, esto es, con igual respecto y consideración. Dworkin distingue dos principios fundamentales y distintos que consideran la igualdad como un ideal político. El primero de ellos exige que el gobierno trate a todos como iguales, es decir, con igual consideración y respeto. El segundo principio exige que el gobierno trate a todos como iguales en la distribución de ciertos recursos vinculados con las oportunidades, o al menos que intente asegurar un estado de cosas en que todos sean iguales. Los recursos y oportunidades han de ser distribuidos, en la medida de lo posible, equitativamente, de manera que la misma porción esté destinada a satisfacer las aspiraciones de cada uno.

La justicia se convierte en el valor omnicomprensivo y esencial de la filosofia moral y jurídica, a la vez que un criterio básico de legitimación y crítica del derecho. Para Platón, la justicia es la virtud fundamental de la cual derivan todas las demás virtudes, pues constituye el principio armónico y ordenador de todas (prudencia o sabiduría, fortaleza o valentía, templanza) y de un Estado justo. La justicia es, según Rawls, la primera virtud de las instituciones sociales. Los utilitaristas piensan, que la única forma de dirigir la sociedad es dando el máximo de bienestar social a sus habitantes; pero Ralws señala que esto contradice claramente una visión de la justicia pública, en muchas ocasiones el bienestar social del grupo aumentaría si estuviéramos dispuestos a sacrificar a una persona en beneficio del resto; pero la mayoría consideraríamos injusto el sacrificio de un inocente. Según John Ralws nadie es un medio para los fines de la sociedad en general, según su principio fundamental. Ralws defiende a ultranza la prioridad de la libertad e individualidad según el principio kantiano "la persona humana es un fin en sí mismo y no un medio". ${ }^{23}$

23 Kant, M, Fundamentación de la metafísica de las costumbres, Espasa-Calpe, trad. de Manuel Garcia Morente, Madrid, 1981 p. 84; Larenz, Karl, Derecho justo, Fundamentos de Ética jurídica, Madrid, Civitas, 2000. 
Siguiendo la tradición contractualista llevada a su punto más alto, Ralws sostiene que los principios de la justicia como estructura de la sociedad son aquellos elegidos mediante un acuerdo original. ${ }^{24}$ Es decir, son elegidos en una posición original de igualdad y libertad (situación hipotética como el estado de naturaleza en la teoría contractual clásica). Los principios se eligen en la posición original tras un velo de ignorancia. La equidad del procedimiento garantiza la equidad del resultado, la justicia como imparcialidad. ${ }^{25}$

Dworkin sigue de cerca el planteamiento ralwsiano de justicia como igualdad y considera éste que podría ser el derecho fundamental más básico, es decir el derecho natural prioritario y fundacional del resto de derechos. En oposición a Hart que defiende el derecho a la libertad, Dworkin siguiendo los pasos de Rawls, el derecho al trato igual, a la equidad que no se reduce sólo a igualdad jurídica, sino a

24 Estos principios de justicia son la que elegirian sujetos agentes perfectamente racionales si tuvieran que decidir desde el velo de la ignorancia, esto es, desconocedores de su identidad, preferencias personales o posición social. El velo de ignorancia es necesario para que se de la mayor imparcialidad posible en el procedimiento de estructuración de la sociedad. Estas condiciones, Ralws cree que los agentes abstractos decidirian asegurar la mayor cantidad de bienes básicos, en previsión de caer en el peor lugar de la sociedad y admitirian la diferencia social de trato en la medida que favoreciese a la posición de los peor situados.

25 Ralws no va a hablar de instituciones, leyes o disposiciones personales justas e injustas, su tema es la justicia social. La justicia de un sistema social depende esencialmente de cómo se asignan los derechos y deberes fundamentales y de las oportunidades económicas de los sectores de la sociedad. Así por ejemplo, la protección jurídica de la libertad de pensamiento, protección jurídica de la libertad de conciencia, la competencia mercantil, la propiedad privada de los medios de producción, la familia monogámica son ejemplos de instituciones sociales más importantes. La primera enmienda de los Estados Unidos de América dice que las libertades básicas, son la libertad de pensamiento y de conciencia, libertades políticas de asociación, las libertades físicas e integridad de la persona, libertades incluidas en el principio de legalidad. Rubio Carracedo, J., "Paradigmas de la obligación política", Sistema, cit., pp. 89-106. Recogido en su libro Paradigmas de la politica. Del Estado justo al Estado legitimo (Platón, Marx, Rawls, Nozick), Antropos, 1990. 
trato igualitario y equilibrado, en este sentido, se decanta más hacia el igualitarismo fundado en la justicia social que hacia un liberalismo politico conservador.

Ronald Dworkin distingue claramente entre igualdad económica de igualdad política. La igualdad politica tiene una intima y estrecha relación con el concepto de democracia, mientras la igualdad económica se refiere a dos modos distintos de justicia. El primero toma en cuenta los recursos mientras el segundo se refiere al bienestar de las personas. Ambos principios de de igualdad vienen desarrollados por dos concepciones de Estado. "La igualdad liberal es igualdad de recursos, no de bienestar". ${ }^{26}$ La igualdad liberal, rechaza el bienestar como métrica de la justicia, a favor de los recursos.

La igualdad debe ser vista, según Dworkin, como igualdad de recursos, entendiendo por tal el conjunto de lo que llama "recursos personales e impersonales". Entre los recursos personales están la salud física y mental, la fuerza, el talento; entre los impersonales, las propiedades, las materias primas, los derechos legales.

Igualmente, el célebre Premio Nóbel de Economía, Amartya Sen comulga plenamente con la propuesta de igualdad de oportunidades de Rawls, sólo con la salvedad de que no quiere reducir la justicia al mero reparto equitativo de bienes básicos. ${ }^{27}$ No es suficiente para alcanzar ciertas cotas de igualdad material tener sólo oportunidades de bienestar, sino que hay que tener capacidad de usarlos, elegir y funcionar con ellos. Los bienes, recursos, ingresos ayudan, pero son insuficientes si faltan las capacidades, entendiendo por capacidad la libertad para buscar los elementos constitutivos del bienestar personal y social. Hay muchas

26 Dworkin, Ronald, Ética privada e igualitarismo politico, Paidós, 1993.

27 Amartya, K. Sen, Bienestar, justicia y mercado, Barcelona, Paidos, 1997. SEN, A., Sobre la desigualdad económica, trad. cast. de Verdeja, I., Barcelona, Editorial Crítica, 1979. 
desigualdades $^{28}$ distintas de la distribución de ingresos y propiedades que contribuyen a disminuir la capacidad de una persona para proponerse metas y poder alcanzarlas. Las desigualdades de género, sociales, de raza, son factores que influyen en la capacidad de conseguir empleo, recibir atención médica o ser tratado equitativamente por la policía. Amartya Sen propone una igualdad más sustantiva que la igualdad formal de oportunidades de Rawls.

\section{CONCEPCIÓN ONTOLÓGICA JURÍDICO-POLÍTICA EN DWORKIN}

El modelo de integración relativa de Ronald Dworkin defiende un iusnaturalismo moderado y crítico que rechaza tanto la tesis que propugnan la separación radical entre el derecho y la moral (iuspositivismo extremo), como la que postula una integración total (iusnaturalismo radical). El representante de esta tesis es Ronald Dworkin, quien propugna que todo ordenamiento jurídico se halla integrado por un conjunto de principios (principles), medidas o programas políticos (policies) y reglas o disposiciones específicas (rules).

Las tesis iusnaturalistas extremas y radicales entrañan una visión idealista, trascendente y abstracta del Derecho, mientras que para Dworkin el derecho y sus valores se sitúan en el plano de la práctica jurídica, en el ámbito de las decisiones judiciales que tienen relación con nuestro derechos fundamentales. Sin duda, el término "iusnaturalismo"29 responde a una expresión enormemente polisémica, equivoca y ambigua que ofrece una gran variedad de sentidos en el ámbito de los estudios jurídico-filosóficos, de aquí,

28 Amartya, K. Sen, Nuevo examen de la desigualdad, Madrid, Alianza, 1995.

29 Eusebio Fernández, "El iusnaturalismo", en Garzón Valdés, Ernesto y Laporta, Francisco José (comps.), El derecho y la justicia, Madrid, CSIC, 1996, p. 267. Fernández, E., Teoría de la justicia y derechos humanos, Madrid, Debate, 1984. pp. 41 y 42. Fernández, E., Estudios de ética jurídica, Madrid, Debate, 1990, p. 41-44. 
que resulte imprescindible atisbar y dilucidar alguno de sus significados. Por "iusnaturalismo" podemos entender una multiplicidad de corrientes doctrinales muy diversas, pero todas ellas con un núcleo común: la creencia en un orden objetivo suprapositivo jurídico de carácter universal, permanente e inviolable que contiene los valores últimos de todo ordenamiento humano.

Una objeción histórica que se le ha realizado al iusnaturalismo es el paso falaz e indebido del ser al deber ser, es decir, la llamada falacia naturalista. ${ }^{30}$ En ella se hace una inferencia errónea al pasar de la naturaleza a la ley, del hecho al valor. Su intento de fundamentar los derechos humanos en una supuesta naturaleza humana fija, indeterminada e inmóvil, hoy por hoy, resulta un intento fallido y fracasado, dado por un lado que nuestra concepción antropológica ha cambiado y, por otro lado, se realiza una inferencia equivocada al deducir de la naturaleza humana (ser) directamente los derechos humanos (deber ser).

Dentro de nuestra tradición multisecular iusnaturalista debemos distinguir dos grandes tendencias que suponen dos grandes versiones del iusnaturalismo. ${ }^{31}$ 1) Iusnaturalismo ontológico, dogmático o radical, que postula un orden de valores producto de un objetivismo metafísico transcendente. En esta corriente podemos insertar autores como Am-

30 Véase Moore, G. E., Principia Ethica, México, UNAM; Hume, D., A Treatise of Human Nature, Londres, Fontana-Collins, 1972. Véase Beuchot, Mauricio "Derecho natural y falacia naturalista", Filosofía y derechos humanos, México, Siglo XXI, p. 135; Finnis, J., Natural Law and Natural Rights, Oxford, Clarendon Press, 1980.

31 1Pérez Luño, Antonio Enrique, Trayectorias contemporáneas de la filosofía y la teoría del derecho, 4a. ed., Lima, Palestra, 2005, p. 41. Savater igualmente ha distinguido entre un uso dogmático y un uso crítico del derecho natural. "El primero es el que busca el establecimiento inexpugnable de la verdad, el segundo un instrumento capaz de descubrir por contraste lo falso. Lo que brinda el derecho natural es un patrón o baremo universal para juzgar la rectitud de los derechos vigentes en cada estado, no un superderecho inmutable cuya autenticidad es base de todos los restantes". Savater, F., "Fundamento y disputa de los derechos humanos", Ética como amor propio, Barcelona, Grijalbo Mondadori, 1988. 
brosetti, Luño Peña, Maritain, Finnis, Villey, Gilson, Millán Puelles, entre otros.

El iusnaturalismo ontológico parte de un realismo metafísico ingenuo, esencialista y trascendente que presupone la existencia de un mundo prefabricado (ready-made-World) o lo que Hilary Putnam manifiesta como el punto de vista de Dios. La verdad para el realista metafísico es un propiedad no-epistémica, es decir, independiente a las cualidades epistémicas de las teorias. Hilary Putnam critica fuertemente esta posición desde la perspectiva epistemológica de lo que denomina "realismo interno".32

2) Iusnaturalismo deontológico, crítico o moderado que no niega la juricidad del derecho positivo injusto, pero establece los criterios para comprobar su disvalor y, por tanto, para fundamentar su crítica y su sustitución por un orden jurídico justo. En esta corriente encontramos pensadores como Bloch, Del Vecchio, Stammler, Legaz Lacambra, Recaséns Siches, Welzel, Dworkin, Pérez Luño, Eusebio Fernandez, Santiago Nino). ${ }^{33}$

32 Hilary Putnam intenta articular una interdependencia entre verdad y racionalidad en un posición denominada "realismo interno" enfrentada tanto a la ingenuidad de las teorías de la verdad-copia-representacionistas ("el punto de vista del ojo de Dios") como a la indolencia del relativismo epistemológico. Putnam, Hilary, Razón, verdad e historia, Madrid, Tecnos, 1988. Por otra parte el iusnaturalismo ontológico parte de una concepción antropológica y metafísica fuertemente determinista y esencialista del ser humano, deberíamos caminar hacia una imagen más proteica, flexible y abierta.

33 En la comunidad iberoamericana, ha existido un tradicional dominio del iusnaturalismo en la filosofía del Derecho y más explícitamente, un iusnaturalismo neoescolástico, fuertemente conservador y dogmático. Esto explica que la aparición de corrientes críticas haya sido más tardía y débil que en Europa o Estados Unidos, y que en algunos casos como México, Chile, Argentina y España la visión iusfilosofica analitica y positivista haya cumplido una función politica e intelectualmente innovadora e incluso crítica ${ }^{20}$ en su momento. Perez Luño, Antonio Enrique, op. cit., p. 42. Pérez Lledó, J. A., “Teorías críticas del Derecho" en Garzòn Valdès, E. y Laporta, Francisco J., El derecho y la justicia, Madrid, Trotta, 1996. 
El iusnaturalismo radical ${ }^{34}$ ha tropezado siempre con el escollo que supone negar la condición de derecho a las legislaciones históricas que no responden a determinados criterios de justicia. Esta postura tiene a su favor el rechazo del relativismo y escepticismo axiológicos, pero en su contra hay que advertir que propugnan un orden ontológico, cerrado y ahistórico de valores metafísicos, eternos e inmutables. El problema consiste en el riesgo de este sector de imponer una "tiranía de valores" a los demás. "Las sociedades abiertas y pluralistas actuales parecen más proclives a admitir un iusnaturalismo racionalista, deontológico y crítico, que las versiones ontológicas que, no obstante, siguen contando con la adhesión de un amplio sector de estudiosos que defienden posiciones confesionales especialmente neotomistas". 35

El iusnaturalismo ha tratado de defender la posición de los derechos humanos como derechos morales tratando de restar importancia al elemento de la positividad de los derechos humanos como aspecto decisivo fundacional de los mismos. Ante esta problemática Carlos Santiago Nino plantea: “[...] tiene pleno sentido preguntarse si los derechos humanos son de índole jurídica o moral o si corresponden a esa categoría mestiza constituida por el derecho natural (o si pueden ser a la vez morales, jurídicos y "jurídico-naturales»"). 36

\title{
VI. LOS DERECHOS HUMANOS COMO TRIUNFOS POLÍTICOS EN EL ESTADO CONSTITUCIONAL
}

\begin{abstract}
"La ignorancia, el olvido o el desprecio de los derechos del hombre son las únicas causas de los males públicos y de la corrupción de los gobiernos". Prólogo de la Declaración de la Asamblea francesa.
\end{abstract}

34 Pérez Luño, op. cit., p. 137.

35 Pérez Luño, Antonio Enrique, op. cit., p. 42.

36 Nino, Carlos Santiago, "El concepto de derechos humanos", Ética y derechos humanos, Un ensayo de fundamentación, Buenos Aires, Astrea del Alfredo, 1989, p. 14. 
El tema de los derechos humanos constituye el central y fundamental de su teoría del Derecho y su filosofia politica de Dworkin. En su famosa obra Taking Rights Seriously, publicada en 1977, Dworkin sostiene una visión clara de los derechos humanos como derechos fundamentales de los ciudadanos, como triunfos políticos ante cualquier decisión arbitraria o abusiva del poder político. Nuestro pensador ha insistido mucho en su teoría político-jurídica en los principios que tienen su origen no tanto en alguna decisión particular de algún legislador, sino en convicciones, prácticas, intuiciones profesionales y populares entendidas en sentido amplio. Y además los principios tienen una peculiaridad: "son proposiciones que describen derechos": ${ }^{37}$ Los derechos se imponen en particular a las "directrices politicas" (policies) definidas en términos utilitaristas. Un derecho es algo que debe ser respetado y satisfecho, aun cuando su respeto y satisfacción vayan contra la directriz politica a favor del interés general. Los derechos, que son descritos a través de los principios pertenecen en parte, no al sistema normativo jurídico, sino a la vida y la cultura: es decir, a la moralidad de una determinada comunidad. El iusnaturalismo moderado de Ronald Dworkin, ${ }^{38}$ por tanto, trata de recuperar la idea de la existencia de unos derechos morales, naturales, previos al Estado y que, en todo caso, sirven de módulo justificador para su operatividad y eficacia práctica, creando

37 Dworkin, R., Taking Rights Seriously, Duckworth, Londres, trad. cast. Los derechos en serio, Barcelona, Ariel, p. 307. La teoría de Ronald Dworkin opera abiertamente dentro del Derecho norteamericano y su filosofia jurídica pone de manifiesto y evidencia la enorme vinculación que existe entre Derecho y moral, en todo sistema jurídico existen principios inmanentes que de alguna manera fundan la interrelación entre Derecho y moral. Estos principios extrajudiciales operan en la interpretación y aplicación de la norma jurídica que realiza el juez en su casuística contextual ordinaria y fáctica. Dworkin, Ronald, Ética privada e igualitarismo político. Barcelona, Paidós, 1993.

38 Dworkin, R., El imperio de la justicia: de la teoría general del derecho e interpretación de los jueces y de la integridad politica como clave de la teoría y la práctica, Barcelona, Gedisa, 1998. 
una protección de los ciudadanos frente al Gobierno. Estos principios morales son vividos por una determinada comunidad y a ellos puede acudir un juez para decidir ante los casos dificiles.

La filosofia político-jurídica de Dworkin se fundamentada principalmente en una concepción de derechos individuales que supone que estos derechos y, sobre todo, el derecho a la igual consideración y respecto significan históricamente un triunfo frente a la mayoría. En este sentido, ningún ordenamiento jurídico, directriz política ni objetivo social colectivo puede rebasar, anular o transgredir este auténtico derecho humano que reside en la igualdad y la dignidad humana. ${ }^{39}$ Esto convierte a los derechos humanos en la instancia legítima última fundamental de toda institución política y jurídica. Las ideas de dignidad humana e igualdad política presiden la noción de derechos individuales, éstas dos categorias se constituyen en baluartes inexpugnables ante los que el poder estatal ha de detenerse para salvaguardar la primacía de la persona según la tradición del liberalismo político; pero no sólo eso, sino que además deben convertirse en faros orientadores de todo Estado democrático y social que se precie.

Cualquiera que declare que se toma los derechos en serio y que elogie a nuestro gobierno por respetarlos debe tener alguna idea de qué es ese algo. Debe aceptar como mínimo una o dos ideas importantes. La primera es la idea, vaga pero poderosa, de la dignidad humana. Esta idea asociada con Kant, pero que defienden filósofos de diferentes escuelas supone que hay maneras de tratar a un hombre que son incongruentes con el hecho de reconocerlo cabalmente como miembro de la comunidad humana y sostiene que un tratamiento tal es profundamente injusto. La segunda es la idea, más familiar, de la igualdad política, que supone que los miembros más débiles de una comunidad política tienen derecho, por parte del Gobierno, a la misma consideración y el

39 Calsamiglia, A., "Estudio preliminar" en Dworkin, R., Los derechos en serio, Barcelona, Ariel, 1999, p.16. 
mismo respecto que se han asegurado para sí los miembros más poderosos, de manera que si algunos hombres tienen libertad de decisión, sea cual fuere el efecto de la misma sobre el bien general entonces todos los hombres tienen que tener la misma libertad. 40

El positivismo jurídico considera que los únicos derechos existentes son los reconocidos positivamente por un determinado sistema jurídico. En oposición a esta concepción positivista simplista y reduccionista Dworkin mantiene que junto a los derechos legales existen derechos morales. Los derechos jurídicos y los derechos morales no pertenecen a órdenes conceptuales distintos, en caso de conflicto entre derechos morales y derechos jurídicos, éstos últimos no triunfan necesariamente sobre aquellos. Según Dworkin el problema de los derechos no se resuelve mediante la positivación o el mero reconocimiento legal porque la frontera o demarcación entre los derechos morales y jurídicos es una frontera difusa, movediza y permeable. Una demarcación no demasiado explícita y clara entre moral y Derecho, derechos humanos y derechos positivos. En este sentido, nos advierte que "la garantía de los derechos individuales es la función más importante del sistema jurídico". ${ }^{41}$

Por consiguiente, Dworkin defiende la prevalencia de unos derechos morales fuertes (strongs rights), ${ }^{42}$ derivados de la tutela de los principios básicos, principalmente, la

40 Dworkin, R., Los derechos en serio, op. cit., p. 295.

41 Calsamiglia, A., op. cit., p. 17.

42 La concepción iusnaturalista de Dworkin se enfrenta a la posición positivista que sostiene que sólo son normas jurídicas aquellas que son reconocidas por su origen fáctico y perfectamente distinguible de las normas morales. Su posición se apoya en la admisibilidad de ciertos tipos de estándares morares como parte del Derecho, el alcance de la discreción judicial y la posibilidad de justificar proposiciones jurídicas sobre la base de prácticas sociales. Estos tres elementos se enfrentan radicalmente a la visión positivista. Véase al respecto el trabajo Nino, Carlos Santiago "Dworkin y la disolución de la controversia positivista versus iusnaturalismo" en Squella Agustín, "Ronald Dworkin", Revista de Ciencias Sociales, Chile, Universidad de Valparaíso, núm. 38, pp. 495-528. 
dignidad humana e igualdad politica, que no pueden ser desconocidos por los poderes públicos. Dworkin sostiene la existencia de derechos preexistentes, sin defender una teoría metafísica concreta. 43 Los individuos tienen derechos, aún cuando éstos no están positivizados en ningún texto legal. Por tanto, al lado de los derechos legales existe otro tipo de derechos cuyo fundamento jamás será el consenso social reconocido en una norma sino, según le hemos visto, un cierto tipo de moralidad básica. Los derechos humanos tienen un marcado carácter moral que posibilita su fundamentación para la teoría y práctica jurídica, por el principio intrínseco de justicia que tienen de forma inherente. El Derecho no es más que un instrumento que tiene como fin tutelar y garantizar los derechos fundamentales frente a las agresiones o violaciones de la mayoría y del gobierno. Por lo que, Dworkin habla de los derechos contra el Gobierno (rights against the Goverment), es decir derechos ${ }^{44}$ cuya violación admitiría y justificaría unos actos de desobediencia frente al gobierno. Estos derechos no son derivados del propio ordenamiento jurídico, sino derechos morales del individuo. En este sentido, la teoría del Ronald Dworkin acerca del Derecho y la justicia es una postura antipositivista en el sentido que sostiene la existencia de derechos preexistentes al reconocimiento legal y positivo del ordenamiento jurídico.

Estos derechos funcionarán como cartas de triunfo al ser invocadas por los ciudadanos; permitirán a los individuos resistirse a decisiones particulares a pesar de que esas decisiones hayan sido alcanzadas por medio del funcionamiento normal de instituciones generales, las cuales no son en sí mismas desafiadas por esta resistencia". ${ }^{45}$

43 De Asis Roig, Rafael, "Dworkin y los derechos en serio", en Squella Agustín, Ronald Dworkin, Revista de Ciencias Sociales, cit.

44 Véase Dworkin, R., Freedom's Law. The Moral Reading of the American Constitution, Harvard University Press, Cambridge, Mass.

45 Dworkin, Ronald, Liberalismo, Constitución y democracia, Buenos Aires, Ed. La isla de la Luna, 2003, p. 32. 
El positivismo jurídico no acepta la idea de que puedan preexistir derechos a cualquier forma de ordenamiento jurídico, es decir, rechaza la idea de que a los individuos se les pueda adjudicar derechos no explícitamente previstos en el conjunto de normas explícitas que componen la totalidad del ordenamiento jurídico de una comunidad. Por tanto, la tesis central del positivismo que defiende la separación radical entre derecho y moral es falsa. No se puede separar razonamiento jurídico del razonamiento moral.

\section{CONCLUSIONES}

En consecuencia, en la visión iusfilosófica de Dworkin constatamos que el razonamiento jurídico depende en gran medida del razonamiento moral, en el sentido en que los principios morales juegan un papel importante y decisivo en el razonamiento jurídico, especialmente en los casos dificiles. Según el profesor Calsamiglia, este filósofo norteamericano intenta construir una tercera vía entre el iusnaturalismo e iuspositivismo 46 desde el modelo reconstructivo social de Rawls. En mi opinión, considero que no se trata de una tercera vía sino e la recuperación y restauración de un iusnaturalismo moderado, crítico y progresista que trata de restaurar la abrupta ruptura neopositivista entre razonamiento moral y razonamiento jurídico, defendido por Bentham, Austin y Hart. Desde este iusnaturalismo deontológico moderado de Dworkin está demostrando lo que Isaah Berlin plantea que existe una serie de valores compartidos, "un mínimo sin el que las sociedades dificilmente podrian sobrevivir". ${ }^{47} \mathrm{La}$ necesidad de aceptar y respetar esos valores es imperiosa y urgente en nuestra actual sociedad. Sin duda, éste es uno de los aspectos más positivos y relevante de la teoría de Dworkin, el reconocer y otorgar un papel predominante den-

46 Calsamiglia, A., op.cit.

47 Berlin, I., El fuste torcido de la humanidad, trad. de J. M. Álvarez Flores, Barcelona, Península, 1992, p. 9. 
tro de la teoría político-jurídica a los principios y valores en las decisiones politicas y jurídicas.

VIII. BIBLIOGRAFÍA

AGUILERA PORTALES, Rafael "La igualdad como valor normativo, axiológico y político fundamental", en FIGUERUELO, Ángela, ¿Igualdad ¿para qué?, Granada, Comares, 2007.

y ESPINO TAPIA, Diana, "Fundamento, naturaleza y garantías jurídicas de los derechos sociales ante la crisis del Estado social", Revista Telemática de Filosofía del Derecho, Madrid, núm. 10, 2006.

ALEXY, Robert, Teoría de la argumentación jurídica, Madrid, CEPC, 1997.

- Teoría de los derechos fundamentales, Madrid, CEPC, 2002.

__ El concepto y la validez del derecho, Barcelona, Gedisa, 1997.

Bernstein, R. J., Praxis y acción, Madrid, Alianza, 1979 (original Praxis and Action, Pensylvania, University of Pensylvania Press, 1971).

BERNSTEIN, R. J., La reestructuración de la teoría social y politica, México, Fondo de Cultura Económica, 1983.

BoBBio, N., El problema del positivismo jurídico, trad. de E. Garzón Valdés, Buenos Aires, Editorial Universitaria, 1965.

_- "La teoría pura del derecho y sus críticos", Contribución a la teoría del derecho.

BLOCH, Ernst, Derecho natural y dignidad humana, trad. de Felipe González Visen, Madrid, 1980.

DE CASTRO CID, B., "Moral y derecho", Lecciones de teoria del derecho y derecho natural, Fernández-Galiano y B. de Castro Cid, 1999. 
DE Asís RoIG, Rafael, Escritos sobre derechos humanos, Lima, Ara editores, 2005.

DÍAZ, Elías, Sociología y filosofía del derecho, Madrid, Taurus, 1999.

DíAZ REVORIO, Francisco Javier, La Constitución abierta y su interpretación, Lima, Palestra, 2004.

DwORKIN, Ronald, "No Right Answer?", en HACKER, P. M. S. y RAZ, J., Law, Morality, and Society. Essays in Honour of H. L. Hart, Oxford, Clarendon Press, 1977.

—_, La filosofía del derecho, México, Fondo de Cultura Económica, 1980.

,What is Equality? Part 1: Equality of Welfare", Philosophy and Public Affairs, 10, núm. 3, 1981.

- "What is Equality? Part 2: Equality of Resources", Philosophy and Public Affairs, 10, núm. 4, 1981.

- "What is Equality? Part 3: The Place of Liberty", Iowa Law Review, núm. 73, 1987.

, "What is Equality? Part 4: Political Equality", University of San Francisco Law Review, núm. 22, 1987.

, "Liberalism", A Matter of Principle, Cambridge, Masachusetts, Harvard University Press, 1985.

—_ La comunidad liberal, Universidad de los Andes, 1996.

—_ Ética Privada e igualitarismo politico, Barcelona, Paidos-UAB, 1993.

, The Law of the Slaves-Catchers", Times Literary Supplement, 5 de diciembre de 1975.

_- Law's Empire, Cambridge, Masachusetts,Harvard University Press, 1986 (traducción al español: El imperio de la justicia: de la teoría general del derecho e interpretación de los jueces y de la integridad politica como clave de la teoría y la práctica, Barcelona, Gedisa, 1998. 
- Los derechos en serio, Barcelona, Ariel, 1995.

- Liberalismo, Constitución y democracia, Buenos Aires, Ed. La isla de la Luna, 2003.

- , Posner, The Problems of Jurisprundence, Havard University Press, 1990.

FERNÁNDEZ, Eusebio, "El iusnaturalismo", en GARZÓN VALDÉS, Ernesto y ESTÉVEZ ARAUJO, J. A., La constitución como proceso y la desobediencia civil, Madrid, Trotta, 1994.

FERRAJOLI, Luigi, Los fundamentos de los derechos fundamentales, Madrid, Trotta, 1999.

—, Derechos y garantias. La ley del más débil, Madrid, Trotta, 1999.

FIOROVANTI, Maurizio, Los derechos fundamentales. Apuntes de historia de las Constituciones, Madrid, Trotta, 1996.

—- Constitución. De la antigüedad hasta nuestros dias, Madrid, Trotta, 2001.

FIGUERUELO BURRIEZA, Ángela, Luces y sombras del tratado constitucional Europeo, Madrid, Dykinson, 2006.

Figueruelo BurriezA, Ángela, "Comentarios al anteproyecto de Ley orgánica de igualdad de mujeres y hombres", Revista Criterio Juridico, Colombia, Santiago de Cali, v. 6, 2006.

GARZÓn VALDÉS E. y LAPORTA, Francisco J., El derecho y la justicia, España, Trotta, 1996.

GRIMM, Dieter, Constitucionalismo y derechos fundamentales, Madrid, Trotta, 2006.

HÄBERLE, Meter, El Estado constitucional, México, UNAM, 2001.

- Libertad, igualdad, fraternidad. 1789 como historia, actualidad y futuro del Estado constitucional (prólogo de Antonio López Pina), Madrid, Trotta, 1998. 
RAFAEL ENRIQUE AGUILERA PORTALES

Habermas, J., Ensayos politicos, Barcelona, Península, 1989.

—_, El discurso de la modernidad, Madrid, Taurus, 1983.

-, Facticidad y validez, Madrid, Taurus, 1992.

_- Identidades nacionales y postnacionales, Madrid, Tecnos, 1989.

—_ La constelación postnacional, trad. cast. de Pere Fabra Abat, prólogo de Camps, V., Barcelona, Paidós, 2000.

, “¿Necesita Europa una Constitución?”, La inclusión del otro (Estudios de teoría politica), Barcelona, Paidos, 1999.

—_, La inclusión del otro. Estudios de teoría politica, Barcelona, Paidos, 1999.

, "De la tolérance religieuse aux droits culturels", $\mathrm{Ci}$ tés, París, núm. 13, 2003.

HURley, S. (comp.), De los derechos humanos, Madrid, Trotta, 1998.

LAPORTA, FRANCISCO, Entre el derecho y la moral, México, Fontamara, 2000.

- (comp.) El derecho y la justicia, Consejo Superior de Investigaciones Científicas, Madrid, Trotta, 1996.

LAREnZ, Karl, Derecho justo, Fundamentos de Ética jurídica, Civitas, Madrid, 2000

LÓPEZ CALERA, N., ¿Hay derechos colectivos? Individualidad y socialidad en la teoría de los derechos, Ariel, Barcelona, 2000

Muguerza, J., "La alternativa del disenso", en PeCESBARBA, G. (ed.), El fundamento de los derechos humanos, Madrid, Debate, 1988.

NINO, Carlos Santiago, "El concepto de derechos humanos", Ética y derechos humanos, Un ensayo de fundamenta- 
ción, Buenos Aires, Astrea del Alfredo, 1989.

PÉREZ LUÑo, Antonio Enrique, Trayectorias contemporáneas de la filosofía y la teoría del derecho, 4a. ed., Lima, Palestra, 2005.

- Teoría del derecho. Una concepción de la experiencia juridica, 1997.

, Derechos humanos. Estado de derecho. Constitución, 6a. ed., Madrid, Tecnos, 1999.

, "El papel de Kant en la formación histórica de los derechos humanos", en PECES-BARBA MARTÍNEZ, G. et al. (dirs.) Historia de los derechos fundamentales, Madrid, Dykinson-Instituto de Derechos humanos Bartolomé de las Casas (Universidad Carlos III), 2001, t. II.

—_ "¿Qué moral? Sobre la justificación moral de la obediencia al Derecho", Sistema, núm. 102, 1991.

PINTORE, Ana, "Derechos insaciables", Los fundamentos de los derechos fundamentales, España, Trotta, 2005.

PRIETO SANCHÍS, Luis, Derechos fundamentales, Neoconstitucionalismo y ponderación judicial, Palestra, Lima, 2002.

_- "La tolerancia y sus limites", Horizontes de la Filosofía del Derecho. Homenaje a Luis García San Miguel, 1, Universidad de Alcalá, 2000.

Kant, I., Die Metaphysik der Sitten, trad. Kant, I., Metafísica de las costumbres, 2a. ed., trad. de A. Cortina y J. Conill, Madrid, Tecnos, 1994.

Kelsen, H., Teoría general del Estado, México, Editora Nacional, 1985.

KymlickA, W., Ciudadanía multicultural, Madrid, Trotta, 1999.

RORTY, R., "Derechos humanos, racionalidad y sentimentalidad", en SHUTE S. y RORTY, R., Pragmatismo y politi$c a$, trad. de Rafael del Águila, Barcelona, Paidós, 1998. 
- ¿Esperanza o conocimiento? Una introducción al pragmatismo, Buenos Aires, FCE, 1987.

RUBIO CARRACEDO, J. L., "Globalización y diferencialidad de los derechos humanos", Revista ALFA (Asociación Andaluza de Filosofía), año IV, núm. 8, 2000.

SMEND, Rudolf, Constitución y derecho constitucional, trad. de José María Beneyto Pérez, Madrid, Centro de Estudios Constitucionales, 1985.

TORRES ESTRADA, Pedro (comp.), Neoconstitucionalismo y Estado de derecho, México, Limusa, 2006.

WAlzer, M., Esferas de la justicia, México, Fondo de Cultura Económica, 1993.

Welzel, H., Introducción a la filosofía del derecho. Derecho natural y justicia material, trad. de F. Gonzalez Vicén, Madrid, Aguilar, 1971.

ZARAGOZA HUERTA, José et al., Los derechos humanos en la sociedad contemporánea, México, Editorial Lago, 2007. 